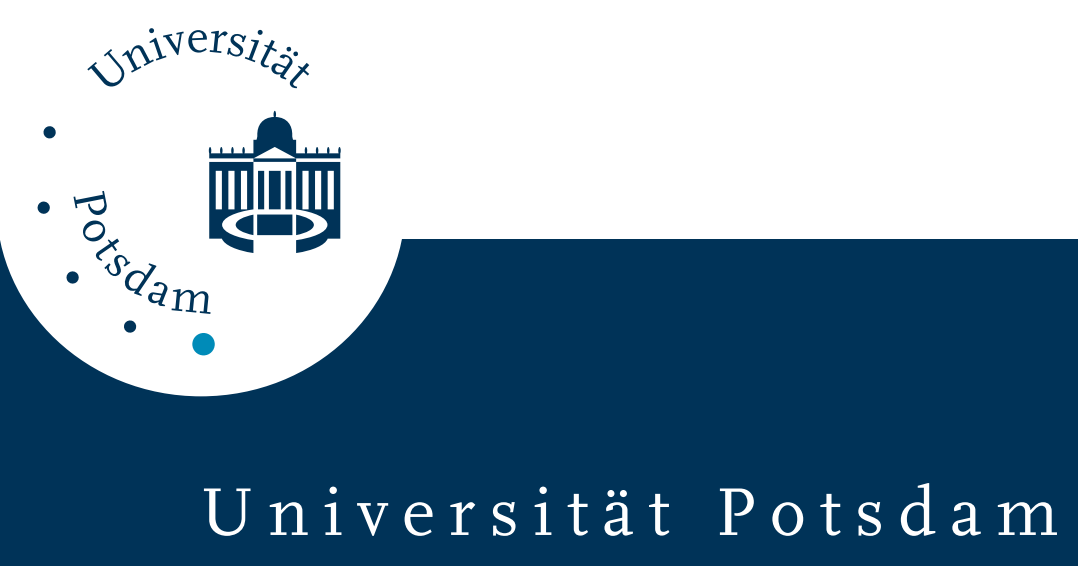

Bettina Scholtka, Mandy Schneider, Ralph Melcher, Tiemo Katzenberger, Daniela Friedrich, Kornelia Berghof-Jäger, Wolfgang Scheppach, Pablo Steinberg

\title{
A gene marker panel covering the Wnt and the Ras-Raf-MEK-MAPK signalling pathways allows to detect gene mutations in $80 \%$ of early (UICC I) colon cancer stages in humans
}

first published in:

Cancer epidemiology 33 (2009), 2, S. 123 - 129,

DOI 10.1016/j.canep.2009.05.001

Postprint published at the Institutional Repository of the Potsdam University:

In: Postprints der Universität Potsdam

Mathematisch-Naturwissenschaftliche Reihe ; 120

http://opus.kobv.de/ubp/volltexte/2010/4458/

http://nbn-resolving.de/urn:nbn:de:kobv:517-opus-44587

Postprints der Universität Potsdam

Mathematisch-Naturwissenschaftliche Reihe ; 120 



\title{
A gene marker panel covering the Wnt and the Ras-Raf-MEK-MAPK signalling pathways allows to detect gene mutations in $80 \%$ of early (UICC I) colon cancer stages in humans
}

\author{
Bettina Scholtka ${ }^{a}$, Mandy Schneider ${ }^{a}$, Ralph Melcher ${ }^{b}$, Tiemo Katzenberger ${ }^{c}$, \\ Daniela Friedrich $^{\mathrm{d}}$, Kornelia Berghof-Jäger ${ }^{\mathrm{d}}$, Wolfgang Scheppach ${ }^{\mathrm{b}}$, Pablo Steinberg ${ }^{\mathrm{a}, *}$ \\ ${ }^{a}$ Institute of Nutritional Science, University of Potsdam, Arthur-Scheunert-Allee 114-116, 14558 Nuthetal, Germany \\ ${ }^{\mathrm{b}}$ Division of Gastroenterology, Department of Medicine II, University of Würzburg, Josef-Schneider-Strasse 2, 97080 Würzburg, Germany \\ ${ }^{\mathrm{c}}$ Institute of Pathology, University of Würzburg, Josef-Schneider-Strasse 2, 97080 Würzburg, Germany \\ d BIOTECON Diagnostics GmbH, Hermannswerder Haus 17, 14473 Potsdam, Germany
}

A R T I C L E I N F O

Article history:

Accepted 5 May 2009

\section{Keywords:}

$A P C$

$B-R A F$

CTNNB1

Colorectal carcinomas

K-RAS

Microsatellite instability

Oncogenes

Tumour suppressor genes

\begin{abstract}
A B S T R A C T
Background: Very recently a gene marker panel that allows the mutational analysis of $A P C, C T N N B 1, B-R A F$ and $K$-RAS was conceived. The aim of the present study was to use the 4-gene marker panel covering the Wnt and Ras-Raf-MEK-MAPK signalling pathways to determine the percentage of sporadic colorectal carcinomas (CRC) carrying at least one of the four above-mentioned genes in a mutated form alone and/ or in combination with microsatellite instability (MSI) and to compare the sensitivity of the gene marker panel used in this study with that of gene marker panels previously reported in the scientific literature. Methods: CTNNB1 and B-RAF were screened by PCR-single-strand conformation polymorphism analysis and $K-R A S$ gene mutations by restriction fragment length polymorphism analysis. For the mutational analysis of the APC gene mutation cluster region (codons 1243-1567) direct DNA sequencing was performed. The U.S. National Cancer Institute microsatellite panel (BAT25, BAT26, D2S123, D5S346 and D17S250) was used for MSI analysis. Results: It could be shown that about $80 \%$ of early stage CRC (UICC stages I and II) and over 90\% of CRC in the UICC stage IV carried at least one mutated gene and/or showed MSI. No significant increase in the gene mutation frequencies could be determined when comparing tumours in the UICC stage I with those in UICC stage IV. Conclusions: When compared with previously published gene marker panels the 4-gene marker panel used in the present study shows an excellent performance, allowing to detect genetic alterations in $80-90 \%$ of human sporadic CRC samples analyzed.
\end{abstract}

\section{Introduction}

Colorectal cancer (CRC) is one of the leading cancer diseases in the Western world. In Germany, more than 70,000 patients are diagnosed every year and 29,000 people die from colorectal cancer [1]. This rate is far too high, taking into account that this cancer type grows very slowly and could be cured if it was diagnosed at an early stage. Several publications have described mutational changes in the different types of CRC including hereditary and sporadic forms. Taken together these studies show very clearly that each of these syndromes has a completely different mutation pattern, thereby affecting different signalling pathways.

\footnotetext{
* Corresponding author at: Institute for Food Toxicology and Analytical Chemistry, University of Veterinary Medicine Hannover, Bischofsholer Damm 15, 30173 Hannover, Germany. Tel.: +49 511856 7545; fax: +49 5118567409.

E-mail address: Pablo.Steinberg@tiho-hannover.de (P. Steinberg).
}

Hereditary syndromes like hereditary nonpolyposis colorectal carcinoma (HNPCC) and familial adenomatous polyposis (FAP) represent $10-15 \%$ of all colorectal carcinomas [2]. Whereas FAP is the result of a germline mutation in the tumour suppressor gene APC [3], about $70 \%$ of HNPCC cases are caused by mutations in the cellular mismatch repair system, whereby the genes mainly affected are $h M L H 1$ and $h M S H 2$ [4,5]. Microsatellite instability (MSI) is found in $75-100 \%$ of HNPCC cases and in $15 \%$ of sporadic cancers [6]. Ninety percent of cancers with mutations in mismatch repair genes show MSI as well.

In the early 1990s Vogelstein and co-workers [7-9] postulated that sporadic CRC arise as the result of a so-called adenomacarcinoma sequence, in which an early bi-allelic inactivation of $A P C$ is followed by an oncogenic mutation of $K-R A S$ and culminates in the inactivation of the tumour suppressor gene p53 at the transition from adenoma to carcinoma. In accordance with this working hypothesis about $60-80 \%$ of human sporadic CRC were shown to harbour mutations in the $A P C$ gene $[10,11]$. Furthermore, 
Sparks et al. [12] suggested that mutations in CTNNB1, which, as $A P C$, is involved in the Wnt signalling pathway and encodes the protein $\beta$-catenin, could uniquely substitute for $A P C$ mutations at early stages of CRC development. Later studies reported that CTNNB1 mutations can be observed in CRC, although at a significantly lower frequency than that originally reported by Sparks et al. [12] and that CTNNB1 mutations are associated with CRC showing MSI [13-16]. Subsequently Johnson et al. [17] showed that CTNNB1 mutations are strongly associated with HNPCC.

In recent years an alternative concept to the above-mentioned adenoma-carcinoma sequence, the so-called serrated pathway, in which hyperplastic polyps give rise to serrated adenomas, these then leading to the development of serrated carcinomas, has been postulated [18-20]. At the molecular level the serrated carcinomas are characterized by MSI, mutation of $B-R A F / K-R A S$ (mutually exclusive) as well as extensive DNA methylation [20], whereby $B$ $R A F / K-R A S$ mutations represent early steps in tumour development along the serrated pathway $[21,22]$.

In a recent study Jass et al. [23] explored the possibility that the early evolution of CRC is not limited to the adenoma-carcinoma sequence and the serrated adenoma pathway, but often combines components of both pathways in a so-called fusion pathway. Specifically, it was suggested that methylation of the DNA repair gene 0-6-methylguanine DNA methyltransferase, mutation of $K$-RAS and inactivation of the tumour suppressor gene $p 53$ provide critical combinations of molecular "cross-over" between the two pathways at the stage of precancerous polyps [23].

In the last two decades research groups worldwide screened thousands of tissue samples from CRC patients with varying panels of molecular gene markers that had been reported to be mutated during CRC development. However, due to the diversity of the CRC types analyzed (in some cases coupled with insensitive screening methods) the sensitivity of the marker panels was rather low or high sensitivities reported in small cohorts were not reproducible if applied to a large number of tissues. Very recently a new panel of primers that allows the analysis of the mutational hotspots within the genes coding for APC, CTNNB1, B-RAF and K-RAS was conceived [24]. The four above-mentioned genes were selected because they are involved in the Wnt and the Ras-Raf-MEK-MAPK signalling cascades (MAPK, mitogen-activated protein kinase; MEK, MAPK/ ERK kinase) and therefore play a substantial role in the adenomacarcinoma and in the serrated adenoma pathways.

The long-term goal is to make use of this new primer panel to develop a non-invasive method to detect colon cancer at a very early stage by stool DNA analysis. In a first step towards this longterm goal the percentage of CRC carrying at least one of the four above-mentioned genes in a mutated form alone and in combination with MSI was determined in 50 sporadic CRC samples by using the new primer panel. Furthermore, the results of this study were compared with those obtained with gene marker combinations previously reported in the scientific literature.

\section{Material and methods}

\subsection{Tissue samples}

Fifty colorectal cancer samples from patients who underwent surgery were obtained from the Department of Medicine at the University of Würzburg (Germany). Permission for the study was given by the Ethics Commission of the University of Potsdam (Decision $3 / 18$ taken on July 28, 2004). After being adequately informed all patients gave their written consent to the scientific use of the tissue samples. The number of tumours corresponding to the UICC tumour stages I, II, III and IV was 10, 19, 10 and 11, respectively.

\subsection{Reagents and kits}

Buffer salts were obtained from AppliChem GmbH (Darmstadt, Germany) and Carl Roth GmbH \& Co. KG (Karlsruhe, Germany). PCR reagents were delivered by BIOLINE GmbH (Luckenwalde, Germany), restriction enzymes by Roche Diagnostics $\mathrm{GmbH}$ (Mannheim, Germany) and New England Biolabs GmbH (Frankfurt, Germany). Kits for purification of PCR products (QIAquick ${ }^{\circledR}$ PCR purification kit) and gel extraction (QIAquick ${ }^{\mathbb{R}}$ gel extraction kit) were purchased from Qiagen GmbH (Hilden, Germany).

\subsection{DNA extraction and fragmentation}

Genomic DNA was extracted from the tissues using a commercial kit (Stratagene Corp.; Amsterdam, Netherlands) and subsequently submitted to whole genome amplification by using the REPLI-g ${ }^{\mathbb{R}}$ Mini kit (Qiagen $\mathrm{GmbH}$ ) according to the manufacturer's instructions.

\subsection{Mutational analysis}

Control fragments for use in PCR-single-strand conformation polymorphism (PCR-SSCP) or in restriction fragment length polymorphism (RFLP) analyses were cloned from human carcinoma cell lines with known mutations or were constructed by site directed mutagenesis. The following mutations were used as positive controls: codon 600 (GTG $\rightarrow$ GAG) in the $B$-RAF gene; codon 33 (TCT $\rightarrow$ TAT), codon 41 (ACC $\rightarrow$ GCC and ACC $\rightarrow$ ATC), codon 45 (TCT $\rightarrow$ CCT and TCT $\rightarrow$ TTT) and del codon 45 (deletion of the complete codon) in CTNNB1; codon 12 (GGT $\rightarrow$ GAT) and codon 13 (GGC $\rightarrow$ GAC) in $K$-RAS.

PCR-SSCP mutational analysis of $B-R A F$ and CTNNB1 was performed as follows: $20 \mathrm{ng}$ genomic DNA were amplified by conventional PCR with sequence-specific primers flanking codons 582-620 and 6-76 [24], respectively. The amplicons were purified from a $2 \%$ agarose gel. Electrophoresis of $4 \mu \mathrm{l}$ denatured product was performed by using a $16 \mathrm{~cm} \times 20 \mathrm{~cm}$ non-denaturing polyacrylamide gel in $1 \times$ TBE ( $90 \mathrm{mM}$ Tris base, $90 \mathrm{mM}$ boric acid, $2 \mathrm{mM}$ EDTA; pH 8.0) with $20 \mathrm{mmol} / \mathrm{l} N$-(2-hydroxyethyl)piperazine-1- $N^{\prime}$-(2-ethanesulfonic acid). In order to detect the $B-R A F$ mutation, a $10 \%$ polyacrylamide gel was used at $18{ }^{\circ} \mathrm{C}$ with $300 \mathrm{~V}$ for $4.5 \mathrm{~h}$. In the case of the CTNNB1 mutation analysis a $13 \%$ gel was run at $26{ }^{\circ} \mathrm{C}$ with $250 \mathrm{~V}$ for $5 \mathrm{~h}$ and an $8 \%$ gel at $21^{\circ} \mathrm{C}$ with $200 \mathrm{~V}$ for $5 \mathrm{~h}$. Gels were silver stained and shifted bands were cut out, reamplified, purified and sequenced.

$K-R A S$ gene mutations were screened by RFLP analysis according to the method described by Schimanski et al. [25]. Briefly, $2 \mu$ l of the whole genome amplification product obtained by using the REPLI-g Mini kit were PCR-amplified with the primer pair Ras A and Ras B (for primer sequences see Schimanski et al. [25]), generating a $166 \mathrm{bp}$ amplicon. The mismatch primer Ras A hybridizing with codons $2-11$ of the $K-R A S$ gene exon 1 introduces a restriction site for $B s t X I$ or $X \mathrm{cmI}$ into the amplicon. In case that a template is mutated in codon 12 or 13 , the restriction site is lost. The subsequent enzymatic restriction leads to an enrichment of mutated DNA strands. Gel bands having the size of the mutated control fragments were cut out and sequenced.

For the mutational analysis of the $A P C$ gene mutation cluster region (codons 1243-1567) direct DNA sequencing was used. Sequencing was performed at GATC Biotech AG (Konstanz, Germany).

\subsection{MSI analysis}

The U.S. National Cancer Institute microsatellite panel (BAT25, BAT26, D2S123, D5S346 and D17S250) was used for MSI analysis 
Table 1

Primer sequences for MSI analysis.

\begin{tabular}{|c|c|c|}
\hline Marker & Sequence & Chromosomal localization \\
\hline D2S123 & $\begin{array}{l}\text { AAACAGGATGCCTGCCTTTA } \\
\text { GGACTTTCCACCTATGGGAC }\end{array}$ & $2 \mathrm{p} 16.3$ \\
\hline D5S346 & $\begin{array}{l}\text { ACTCACTCTAGTGATAAATCGGG } \\
\text { AGCAGATAAGACAGTATTACTAGTT }\end{array}$ & $5 q 22.2$ \\
\hline BAT25 & $\begin{array}{l}\text { TCGCCTCCAAGAATGTAAGT } \\
\text { TCTGCATTTTAACTATGGCTC }\end{array}$ & $4 q 12$ \\
\hline BAT26 & $\begin{array}{l}\text { TGACTACTTTTGACTTCAGCC } \\
\text { AACCATTCAACATTTTTAACCC }\end{array}$ & $2 \mathrm{p} 16$ \\
\hline D17S250 & $\begin{array}{l}\text { GGAAGAATCAAATAGACAAT } \\
\text { GCTGGCCATATATATATTTAAACC }\end{array}$ & $17 q 11.2-17 q 12$ \\
\hline
\end{tabular}

[26]. The corresponding primer sequences are shown in Table 1. For PCR one of the primers of each primer pair is labeled with a fluorescent dye (Cy 5 and Cy 5.5; TIB MolBiol, Berlin, Germany) that enables detection of the resulting PCR product. PCR was performed in a $25 \mu \mathrm{l}$ reaction mix containing $50 \mathrm{nM}$ primers, $200 \mu \mathrm{M}$ dNTPs, $1.5 \mathrm{mM} \mathrm{MgCl}_{2}$ in $1 \times$ PCR buffer, $50 \mathrm{ng}$ template DNA, and $0.4 \mathrm{U}$ Taq Polymerase. Initial denaturation for $3 \mathrm{~min}$ at $96{ }^{\circ} \mathrm{C}$ was followed by 33 cycles at $96{ }^{\circ} \mathrm{C}$ for $20 \mathrm{~s}, 58^{\circ} \mathrm{C}$ for $20 \mathrm{~s}$ and $72{ }^{\circ} \mathrm{C}$ for $30 \mathrm{~s}$. Electrophoretic separation of the amplified PCR products was performed using a CEQ8000 capillary electrophoresis system (Beckman-Coulter, Krefeld, Germany). An external size standard allows size determination of the PCR products. Carcinomas were scored as high MSI (MSI-H) when $\geq 2$ markers showed instability and as low MSI (MSI-L) when 1 marker displayed instability.

\subsection{Statistical analysis}

The Fischer's exact test was applied for comparison of the categorical variables. All tests were two-sided. Probability $(P)$ values of less than 0.05 were considered to be statistically significant. All data were analyzed with the statistical software SPSS version 11.0 (SPSS Inc., Chicago, USA). In order to perform the Fischer's exact test, the data for the distal colon and the rectum were grouped together.

\section{Results}

Clinicopathological data regarding the patients and the 50 tumours analyzed are summarized in Table 2. Patients were on average 67.8 years old; 27 were male and 23 female. The mean age of the patients with a CRC in the UICC stage I was somewhat higher than that of patients with CRC in the UICC stages II-IV. However, a detailed analysis of the data revealed that most of the patients with

Table 2

Patient and tumour characteristics.

\begin{tabular}{lllll}
\hline & UICC I & UICC II & UICC III & UICC IV \\
\hline $\begin{array}{lllll}\text { Gender, } n \\
\quad \text { Male/female }\end{array}$ & $4 / 6$ & $9 / 10$ & $8 / 2$ & $6 / 5$ \\
$\begin{array}{l}\text { Mean age, years } \\
\quad \text { (range) }\end{array}$ & 71.1 & 66 & 68.9 & 65 \\
Tumour location & $(53-89)$ & $(30-78)$ & $(54-90)$ & $(44-83)$ \\
$\quad$ & & & & \\
$\quad$ Proximal colon & 4 & 9 & 4 & 4 \\
$\quad$ Distal colon & 1 & 2 & 1 & 2 \\
Rectum & 5 & 8 & 5 & 5 \\
Differentiation grade, $n$ & $n$ & & & \\
1 & 1 & 0 & 0 & 0 \\
2 & 8 & 16 & 8 & 5 \\
3 & 1 & 3 & 2 & \\
\hline
\end{tabular}

CRC in the UICC stages I-IV were 55-75 years old (UICC I: 7/10; UICC II: $16 / 19$; UICC III: 7/10; UICC IV: $8 / 11$ ), only one or two patients in each group being younger than 55 . Furthermore, no significant association between the age of the patients and the frequency of a certain gene mutation/MSI was found.

Twenty-one tumours were located in the proximal colon including caecum, ascending colon, hepatic flexure, transverse colon and splenic flexure, 6 tumours were located in the distal colon, consisting of the descending colon and sigmoid colon, and 23 were located in the rectal part composed of the rectosigmoid junction and rectum. Differentiation of tumours decreased with progression of the disease, the number of dedifferentiated tumours (grade 3 ) in UICC stages I, II, III and IV being 1, 3, 2 and 5, respectively. During the 69 months following surgery 4 patients showed disease recurrence ( 1 stage II patient and 3 stage III patients) and 14 patients died from cancer ( 4 out of 10 stage III patients and 10 out of 11 stage IV patients).

Mutations verified by DNA sequencing as well as MSI status are shown in Table 3. Overall, 43 mutations and 10 cases of MSI were detected. APC was the most frequently mutated gene among the examined targets (22 mutations) followed by K-RAS (12 mutations), $B-R A F$ (7 mutations) and CTNNB1 (2 mutations). The same was true for the mutations within every single tumour stage. However, no significant increase in the amount of mutations or in the number of tumours with MSI was observed between the different tumour stages.

All the mutations detected in $K-R A S, B-R A F$ and CTNNB1 were single base substitutions, whereas in the case of $A P C$ insertions and deletions were more frequent than single base substitutions (Table 3). The mutations detected in the K-RAS gene affected eleven times codon 12 and once codon 13 . All seven mutations detected in the $B-R A F$ gene affected codon 600 , while two CTNNB1 mutations, affecting once codon 41 and once codon 45, were identified. Whereas each of the single base substitutions in $K-R A S, B-R A F$ and CTNNB1 leads to the exchange of an amino acid in the corresponding gene product, the three single base substitutions in the APC gene results in a stop codon leading to protein truncation. Deletions in $A P C$ were detected in 11 cases, insertions in 8 cases. Codon 1309 (deletion of 5 bp), codon 1400 (deletion of a single $\mathrm{C}$ ) and codon 1556 (insertion of a single A) of the APC gene were found to be modified in two tumour samples each. All determined deletions or insertions cause frameshifts. Concomitant mutations of $K-R A S$ and $A P C$ within the same sample were found in 6 out of 50 tumours and mutations of CTNNB1 and APC within the same sample in 1 out of 50 tumours.

By using the selected primer panel mutations were detected in 8 out of 10 stage I carcinomas, whereby 2 carcinomas were mutated in the K-RAS as well as in the APC gene. The percentage of mutated tumours in stages II-IV was 74\% (18 mutations in 19 stage II carcinomas, including three carcinomas with mutations in $K-R A S$ as well as in the APC gene and one carcinoma with a mutation in the APC as well as in the CTNNB1 gene), 50\% (5 mutations in 10 stage III carcinomas) and $82 \%$ (10 mutations in 11 stage IV carcinomas including one tumour with a mutated $A P C$ as well as a mutated $K$-RAS gene), respectively (Table 4 ). Taken together, 36 out of 50 carcinomas (72\%) carried at least one mutation in the APC, $K$ $R A S, B-R A F$ or CTNNB1 gene.

MSI was detected in 10 out of 50 tumours. Four out of these 10 MSI-positive tumours showed a low level (MSI-L) and the other 6 MSI-positive tumours a high level (MSI-H) of MSI (Table 3). The MSI frequencies were 3 out of 10 for stage I tumours, 4 out of 19 for stage II tumours and 3 out of 11 for stage IV tumours. No MSI was found in stage III tumours.

About half (19/40) of the microsatellite stable (MSS) tumours contained mutations in the APC gene, $11 / 40$ had mutations in $K$ RAS, 3/40 in $B-R A F$ and $1 / 40$ in CTNNB1. In the case of the 
Table 3

Mutations and MSI status of CRC tissues (UICC stages I-IV).

\begin{tabular}{|c|c|c|c|c|c|c|c|}
\hline \multirow{2}{*}{$\begin{array}{l}\text { Tumour } \\
\text { stage (UICC) }\end{array}$} & \multirow[t]{2}{*}{ Patient no. } & \multirow[t]{2}{*}{ Tumour location $^{a}$} & \multirow[t]{2}{*}{ MSI status ${ }^{\mathrm{b}}$} & \multicolumn{4}{|l|}{ Mutations } \\
\hline & & & & K-ras & B-raf & CTNNB1 & APC \\
\hline I & 1 & 1 & MSS & $\mathrm{Cd} 12 \mathrm{GGT} \rightarrow \mathrm{GTT}$ & & & Cd 1509 Ins $^{\mathrm{c}} \mathrm{A}$ \\
\hline I & 3 & 11 & MSS & & & & Cd 1361 Del C \\
\hline I & 6 & 10 & MSS & & & & \\
\hline I & 8 & 1 & MSI-L & $\mathrm{Cd} 12 \mathrm{GGT} \rightarrow \mathrm{GAT}$ & & & Cd 1427 Del CC \\
\hline I & 9 & 2 & MSI-H & & & $\mathrm{Cd} 45 \mathrm{TCT} \rightarrow \mathrm{GCT}$ & \\
\hline I & 33 & 7 & MSS & & & & Cd 1465 Del AG \\
\hline I & 34 & 9 & MSS & & & & Cd 1505 Ins T \\
\hline I & 37 & 1 & MSI-H & & $\mathrm{Cd} 600 \mathrm{GTG} \rightarrow \mathrm{GAG}$ & & \\
\hline I & 39 & 12 & MSS & & & & Cd 1438 Del A \\
\hline I & 49 & 8 & MSS & & & & \\
\hline II & 7 & 6 & MSS & $\mathrm{Cd} 12 \mathrm{GGT} \rightarrow \mathrm{GAT}$ & & & \\
\hline II & 10 & 2 & MSI-L & & $\mathrm{Cd} 600 \mathrm{GTG} \rightarrow \mathrm{GAG}$ & & \\
\hline II & 17 & 8 & MSS & & & & Cd 1295 Del A \\
\hline II & 19 & 2 & MSS & $\mathrm{Cd} 12 \mathrm{GGT} \rightarrow \mathrm{TGT}$ & & & Cd 1556 Ins A \\
\hline II & 22 & 9 & MSS & $\mathrm{Cd} 12 \mathrm{GGT} \rightarrow \mathrm{GTT}$ & & & Cd $1322 \mathrm{GAA} \rightarrow$ TAA STOP \\
\hline II & 24 & 10 & MSI-H & & & & Cd 1556 Ins A \\
\hline II & 25 & 2 & MSI-H & & & & \\
\hline II & 27 & 5 & MSS & & $\mathrm{Cd} 600 \mathrm{GTG} \rightarrow \mathrm{GAG}$ & & \\
\hline II & 30 & 2 & MSS & & $\mathrm{Cd} 600 \mathrm{GTG} \rightarrow \mathrm{GAG}$ & & \\
\hline II & 31 & 8 & MSS & & & & \\
\hline II & 32 & 4 & MSS & $\mathrm{Cd} 12 \mathrm{GGT} \rightarrow \mathrm{TGT}$ & & & Cd 1450 CGA $\rightarrow$ TGA STOP \\
\hline II & 35 & 7 & MSS & & & & \\
\hline II & 36 & 1 & MSS & $\mathrm{Cd} 13 \mathrm{GGC} \rightarrow \mathrm{GAC}$ & & & \\
\hline II & 41 & 11 & MSS & & & $\mathrm{Cd} 41 \mathrm{ACC} \rightarrow$ ATC & Cd 1309 Del 5 bp \\
\hline II & 42 & 11 & MSS & & & & \\
\hline II & 44 & 10 & MSS & & & & \\
\hline II & 46 & 4 & MSS & $\mathrm{Cd} 12 \mathrm{GGT} \rightarrow \mathrm{TGT}$ & & & \\
\hline II & 47 & 10 & MSS & & & & Cd 1294 Del CA \\
\hline II & 48 & 2 & MSI-H & & $\mathrm{Cd} 600 \mathrm{GTG} \rightarrow \mathrm{GAG}$ & & \\
\hline III & 4 & 9 & MSS & & & & \\
\hline III & 5 & 12 & MSS & & & & \\
\hline III & 15 & 1 & MSS & & & & Cd 1400 Del C \\
\hline III & 16 & 4 & MSS & & & & Cd 1394 Ins CAGTTCACTT \\
\hline III & 20 & 8 & MSS & $\mathrm{Cd} 12 \mathrm{GGT} \rightarrow \mathrm{GAT}$ & & & \\
\hline III & 21 & 2 & MSS & & $\mathrm{Cd} 600 \mathrm{GTG} \rightarrow \mathrm{GAG}$ & & \\
\hline III & 23 & 3 & MSS & & & & \\
\hline III & 38 & 7 & MSS & & & & \\
\hline III & 40 & 10 & MSS & & & & \\
\hline III & 50 & 11 & MSS & & & & Cd 1472 Ins 98 bp \\
\hline IV & 2 & 9 & MSS & & & & Cd 1371 Ins A \\
\hline IV & 11 & 2 & MSI-L & & & & Cd $1400 \mathrm{Del} \mathrm{C}$ \\
\hline IV & 12 & 10 & MSS & & & & Cd 1309-1311 Del AAAGA \\
\hline IV & 13 & 10 & MSS & & & & Cd 1411 Del T \\
\hline IV & 14 & 1 & MSI-L & & & & \\
\hline IV & 18 & 1 & MSS & & & & Cd 1414 Ins T \\
\hline IV & 26 & 7 & MSS & & & & \\
\hline IV & 28 & 5 & MSI-H & & $\mathrm{Cd} 600 \mathrm{GTG} \rightarrow \mathrm{GAG}$ & & \\
\hline IV & 29 & 11 & MSS & $\mathrm{Cd} 12 \mathrm{GGT} \rightarrow \mathrm{TGT}$ & & & \\
\hline IV & 43 & 10 & MSS & $\mathrm{Cd} 12 \mathrm{GGT} \rightarrow \mathrm{GAT}$ & & & \\
\hline IV & 45 & 7 & MSS & $\mathrm{Cd} 12 \mathrm{GGT} \rightarrow \mathrm{GAT}$ & & & Cd 1553 GAA $\rightarrow$ TAA STOP \\
\hline
\end{tabular}

a Tumour location: 1: caecum; 2: ascending colon; 3: hepatic flexure; 4: colon transversum; 5: splenic flexure; 6: descending colon; 7: sigmoid; 8: rectosigmoid; 9: rectum $<4 \mathrm{~cm} ; 10$ : rectum $<8 \mathrm{~cm} ; 11$ : rectum $<12 \mathrm{~cm} ; 12$ : rectum $>12 \mathrm{~cm}$.

b MSS: microsatellite stable; MSI-L: low microsatellite instability; MSI-H: high microsatellite instability

c Del: deleted; Ins: inserted.

microsatellite unstable (MSI-L and MSI-H) tumours $(n=10)$ three samples carried a mutated $A P C$, one sample a mutated $K-R A S$, one sample a mutated CTNNB1 and four samples a mutated $B-R A F$ (Table 5). The correlation between $B-R A F$ mutation and MSI was statistically significant $(P=0.023)$.

Overall, 38/50 tumours were at least positive for one of the examined tumour markers (i.e. microsatellite instability or a

Table 4

Sensitivity of the gene marker panel with and without MSI.

\begin{tabular}{llllll}
\hline $\begin{array}{l}\text { Sensitivity of CRC } \\
\text { detection (\%) }\end{array}$ & UICC I & UICC II & UICC III & UICC IV & Total \\
\hline $\begin{array}{l}\text { Mutation markers } \\
\text { Mutation markers + MSI }\end{array}$ & 80 & 74 & 50 & 82 & 72 \\
\hline
\end{tabular}

mutation in APC, K-RAS, B-RAF or CTNNB1). Thus, MSI analysis increased the percentage of tumours being positive for at least one of the examined tumour markers to $79 \%$ in the case of stage II carcinomas and to $91 \%$ in the case of stage IV carcinomas (Table 4 ). MSI did not enhance the percentage of tumours being positive for at least one of the examined tumour markers in the case of stage I and stage III tumours.

Table 5

Number of MSS, MSI-L and MSI-H tumours with a specific gene mutation.

\begin{tabular}{lclll}
\hline Gene & MSS & MSI-L & MSI-H & MSI-L + MSI-H \\
\hline APC & 19 & 2 & 1 & 3 \\
CTNNB1 & 1 & 0 & 1 & 1 \\
K-RAS & 11 & 1 & 0 & 1 \\
$B-R A F$ & 3 & 1 & 3 & 4 \\
\hline
\end{tabular}


Table 6

Number of tumours with a specific gene mutation in the proximal colon, in the distal colon and in the rectum.

\begin{tabular}{lllll}
\hline Localization & APC & CTNNB1 & K-RAS & B-RAF \\
\hline Proximal colon & $8 / 22$ & $1 / 2$ & $6 / 12$ & $7 / 7$ \\
Distal colon & $2 / 22$ & $0 / 2$ & $2 / 12$ & $0 / 7$ \\
rectum & $12 / 22$ & $1 / 2$ & $4 / 12$ & $0 / 7$ \\
\hline
\end{tabular}

Table 7

Number of MSS, MSI-L and MSI-H tumours in the proximal colon, in the distal colon and in the rectum.

\begin{tabular}{lllll}
\hline Localization & MSS & MSI-L & MSI-H & MSI-L + MSI-H \\
\hline Proximal colon & $12 / 21$ & $4 / 21$ & $5 / 21$ & $9 / 21$ \\
Distal colon & $6 / 6$ & $0 / 6$ & $0 / 6$ & $0 / 6$ \\
Rectum & $22 / 23$ & $0 / 23$ & $1 / 23$ & $1 / 23$ \\
\hline
\end{tabular}

In the case of $A P C 19$ out of 22 gene mutations were detected in MSS, 2 out of 22 in MSI-L and 1 out of 22 in MSI-H carcinomas (Table 5). Eleven out of $12 \mathrm{~K}$-RAS mutations were detected in MSS and 1 out of 12 in MSI-L carcinomas. One CTNNB1 mutation was identified in a MSS and one in a MSI-H tumour. Three out of seven $B-R A F$ mutations were detected in MSS, one out of seven in MSI-L and three out of seven in MSI-H carcinomas.

In a last step the correlation between tumour location and gene mutations/MSI status of tumours was evaluated. The number of proximal colon, distal colon and rectum carcinomas carrying gene mutations was $18 / 21,3 / 6$ and $15 / 23$, respectively (Table 6 ). Mutations affecting the Wnt pathway (APC and CTNNB1) were significantly more frequent in the colorectum $(P=0.018)$, whereas mutations in $B-R A F$ and $K-R A S$ genes tended to be more frequent in proximal colon tumours. In the case of $B-R A F$ all mutations were found in proximal colon carcinomas, so that this correlation showed a high statistical significance $(P=0.001)$. Nearly all $(9 / 10)$ tumours showing MSI were present in the proximal colon (Table 7), where they accounted for $43 \%$ of the tumours. The association of MSI with tumours developing in the proximal colon was highly significant as well $(P=0.001)$. In contrast, in the rectum only 1 out of 23 tumours showed MSI. There were no tumours with MSI in the distal colon.

\section{Discussion}

By combining the use of a novel primer panel [24] with a MSI analysis it could be shown that about $80 \%$ of early stage CRC (UICC stages I and II) and over $90 \%$ of CRC in the UICC stage IV carried at least one mutated gene and/or showed MSI. The fact that only one half of the CRC in the UICC stage III were "positive" for at least one of the tumour markers studied remains presently unexplained. Nevertheless, the mutation frequencies of all four genes analyzed in the present report are within the range of those of previous studies [16,27-29], in which some of the genes screened in the present study were analyzed together with other gene markers. Interestingly, no significant increase in the mutation frequencies of all four genes studied could be determined when comparing tumours in the UICC stage I with those in UICC stage IV. It is assumed that the marker genes analyzed represent early and initiating mutations in CRC development, so that one would not expect to see an increase in the mutation frequencies of these genes but rather mutations in further target genes as tumours progress from benign to malignant stages, as previously pointed out for APC mutations [10].

In a next step the ability of the primer panel used in the present study to detect mutated genes in CRC samples was compared with that of previously published and often cited gene marker combinations (Table 8). Table 8 shows that the percentage of CRC carrying certain gene mutations in previous publications varies between $55 \%$ and $87 \%$ [16,29-33]. If one takes into account that three out of six gene marker combinations $[16,30,32]$ detect mutations in $\leq 60 \%$ of the tumours analyzed and that in one study [31] the CTNNB1 status was analyzed by immunohistochemistry, the primer panel [24] used in the present study shows an excellent performance. In particular, it should be pointed out that with the primer combination used gene mutations were detected in $80 \%$ of the analyzed sporadic CRC in UICC stage I, a percentage not achieved with any of the previously published gene marker panels. The results obtained in previous studies as well as those in the present report show that in about $10-20 \%$ of CRC up to now not further characterized genetic alterations might occur and that colorectal cancer might even develop along a pathway other than the adenoma-carcinoma sequence [7-9], the serrated adenoma pathway [18-20] or the fusion pathway [23].

The assumption that the gene panel analyzed in the present study as well as MSI play a decisive role in colon cancer development is strongly supported by the data of a very recent oncogenetic tree analysis performed on 971 colon tumours by Sweeney et al. [34]. An oncogenetic tree is a model intended to describe the pathways and sequence of somatic alterations in carcinogenesis without assuming that tumours will fall in mutually exclusive categories. The oncogenetic tree analysis resulted in a reproducible tree with three branches: (1) the first branch was initiated by the methylation of "methylation in tumour" (MINT) sites, predisposing to MSI, methylation of MLH1 and TP16, and B-RAF mutation; (2) the second branch was initiated by an $A P C$ mutation and followed by a p53 mutation; (3) the third

Table 8

Comparison of the mutational analysis results obtained in the present study with those obtained by using different gene marker combinations previously published in the literature.

\begin{tabular}{|c|c|c|c|c|c|c|c|c|c|c|}
\hline Reference & $n^{\mathrm{a}}$ & $A P C^{b}$ & $K R A S^{\mathrm{b}}$ & $p 53^{\mathrm{b}}$ & $B R A F^{\mathrm{b}}$ & $C T N N B 1^{\mathrm{b}}$ & $\operatorname{Axin} 2^{\mathrm{b}}$ & $\mathrm{MSI}^{\mathrm{c}}$ & MLH $1{ }^{\mathrm{d}}$ hypermethylation & $\%$ \\
\hline Deuter and Müller [30] & 23 & 22 & 22 & 43 & & & & & & 56 \\
\hline Zhang et al. [31] & 74 & & 42 & & & $27^{f}$ & & & & 78 \\
\hline Domingo et al. [32] & 40 & 25 & 20 & 22.5 & 30 & & 20 & $100^{\mathrm{g}}$ & 27.5 & 60 \\
\hline Fransén et al. [33] & 130 & 29 & 40 & 42 & 11.5 & 0.8 & & 9 & & 78 \\
\hline Conlin et al. [29] & 107 & 56 & 27 & 61 & & & & & & 87 \\
\hline Lüchtenborg et al. [16] & 656 & 37 & 36 & & & 1 & & & & 55 \\
\hline Present study & 50 & 44 & 24 & & 14 & 4 & & 18 & & $80-91$ \\
\hline
\end{tabular}

a Number of carcinoma samples analyzed.

b Percentage of carcinoma samples carrying the corresponding gene in a mutated form.

c Percentage of carcinoma samples showing MSI.

d Percentage of carcinoma samples showing MLH1 hypermethylation.

e Percentage of carcinoma samples carrying at least one of the markers used in each individual study.

${ }^{\mathrm{f}}$ Activated $\beta$-catenin, determined by immunohistochemistry.

g Only tumours showing MSI were analyzed. 
branch was due to a K-RAS mutation and was not followed by any other genetic alteration [34].

MSI was detected in 10 out of 50 tumour samples, whereby 4 were classified as MSI-L and 6 as MSI-H tumours. By including the MSI analysis as a further "tumour marker" the sensitivity of the 4gene marker panel to detect tumours in the UICC stages II and IV increased by $5 \%$ and $9 \%$, respectively, while it did not result in an increase of sensitivity in the case of tumours in the UICC stages I and III. Overall, a modest increase of about $4 \%$ was recorded, which is in accordance with the fact that MSI is observed much more frequently in hereditary syndromes such as HNPCC and FAP than in sporadic CRC [6].

$A P C$ and $K$-RAS were by far more frequently mutated in MSS tumours than in MSI tumours. In the case of APC similar results have been reported by Thorstensen et al. [35], whereas in the case of $K-R A S$ Konishi et al. [36] and Jass et al. [37] have shown that it is more frequently mutated in MSI-L than in MSS tumours. The CTNNB1 gene was only found to be mutated in 2 out of 50 tumours, which is in agreement with previously published data reporting that CTNNB1 mutations were present in up to $3 \%$ of the sporadic CRC analyzed [13-16] and that they are mainly associated with HNPCC [17]. B-RAF mutations were found to be present in four MSI-L/H and in three MSS tumours, the mutation frequency being in the range of that reported by Fransén et al. [33].

In the present study all tumours carrying a mutated $B-R A F$ gene and 9 out of 10 tumours showing MSI arose in the proximal colon. The results presented herein are in accordance with the observation by Domingo et al. [32] that $B-R A F$ mutations are strongly associated with proximal DNA mismatch repair-deficient CRC. All in all 9 out of 21 proximal tumours showed MSI, a percentage that is similar to that previously reported by Thibodeau et al. [38].

In contrast, $A P C$ gene mutations were more frequently detected in the rectum than in the proximal and distal colon. This observation is in line with the suggestion that toxic compounds in food (e.g. heterocyclic aromatic amines, HCA) may remain quite a long time in direct contact with the epithelial cells in the distal colon and rectum mucosa prior to evacuation, thus facilitating the uptake of these compounds in this particular part of the gastrointestinal tract. Furthermore, it has been shown that male rats fed 2-amino-1-methyl-6-phenylimidazo[4,5- $b$ ]pyridine (PhIP), the most abundant HCA in cooked meat, develop colon tumours, in which specific-1G mutations within $5^{\prime}$-GGGA-3' sequences of the APC gene were detected $[39,40]$. Moreover, the same authors suggested that these specific mutations could be useful for mutational fingerprinting of human cancers. None of the colon cancer tissues analyzed in the present study carried such mutations. This could be due to the fact that the above-mentioned PhIP-induced APC mutations are only observed in rats, that the patients did not take up significant amounts of PhIP or that the PhIP-induced gene mutation pattern in humans is different from that in rats.

In the present study the mean age of the patients with CRC in the UICC stage I was slightly higher than that of patients with CRC in the UICC stages II-IV. Regarding the association of gene mutations with tumour location one could argue that age possibly is a confounder. Although no obvious association between the age of the patients and the frequency of a certain gene mutation/MSI was observed, this point cannot be ultimately cleared due to the low sample size.

Taken together the results presented in this study show that: (1) the combined use of a 4-gene marker panel [24] together with an MSI analysis allows to detect genetic alterations in $80-90 \%$ of human CRC samples (UICC stages I-IV); (2) the primer combination alone allows to detect gene mutations in $80 \%$ of CRC in UICC stage I. At the present time the same primer combination is being used to analyze genetic alterations in hyperplastic polyps and adenomas removed from human colon.

\section{Conflict of interest statement}

Regarding the primer combination used in this study the University of Potsdam (Potsdam, Germany) has applied for an international patent and Bettina Scholtka and Pablo Steinberg are named as inventors in this application.

\section{Acknowledgements}

We thank Mrs. Ingrid Zschaler for excellent technical assistance. This work was supported by grant 0313322 from the Bundesministerium für Bildung und Forschung, Germany.

\section{References}

[1] Gesellschaft der epidemiologischen Krebsregister in Deutschland e. V. and RKI Cancer in Germany. 5th ed. Saarbrücken; 2006.

[2] Houlston RS, Collins A, Slack J, Morton NE. Dominant genes for colorectal cancer are not rare. Ann Hum Genet 1992; 56:99-103.

[3] Groden J, Thliveris A, Samowitz W, Carlson M, Gelbert L, Albertsen H, et al Identification and characterization of the familial adenomatous polyposis col gene. Cell 1991; 66:589-600.

[4] Liu B, Parsons R, Papadopoulos N, Nicolaides NC, Lynch HT, Watson P, et al. Analysis of mismatch repair genes in hereditary non-polyposis colorectal cancer patients. Nat Med 1996; 2:169-74.

[5] Peltomäki P, Vasen HF. Mutations predisposing to hereditary nonpolyposis colorectal cancer: database and results of a collaborative study. The International Collaborative Group on Hereditary Nonpolyposis Colorectal Cancer. Gastroenterology 1997;113:1146-58.

[6] Aaltonen LA, Peltomäki P, Leach FS, Sistonen P, Pylkkänen L, Mecklin JP, et al Clues to the pathogenesis of familial colorectal cancer. Science 1993; 260 : 812-6.

[7] Fearon ER, Vogelstein B. A genetic model for colorectal tumorigenesis. Cell 1990; 61:759-67.

[8] Vogelstein B, Kinzler KW. The multistep nature of cancer. Trends Genet 1993 9:138-41.

[9] Kinzler KW, Vogelstein B. Lessons from hereditary colorectal cancer. Cell 1996; 87:159-70.

[10] Powell SM, Zilz N, Beazer-Barclay Y, Bryan TM, Hamilton SR, Thibodeau SN et al. APC mutations occur early during colorectal tumorigenesis. Nature 1992 359:235-7.

[11] Fearnhead NS, Britton MP, Bodmer WF. The ABC of APC. Hum Mol Genet 2001; 10:721-33.

[12] Sparks AB, Morin PJ, Vogelstein B, Kinzler KW. Mutational analysis of the APC beta-catenin/Tcf pathway in colorectal cancer. Cancer Res 1998; 58:1130-4.

[13] Mirabelli-Primdahl L, Gryfe R, Kim H, Millar A, Luceri C, Dale D, et al. Betacatenin mutations are specific for colorectal carcinomas with microsatellite instability but occur in endometrial carcinomas irrespective of mutator pathway. Cancer Res 1999; 59:3346-51.

[14] Fukushima H, Yamamoto H, Itoh F, Horiuchi S, Min Y, Iku S, et al. Frequent alterations of the beta-catenin and TCF- 4 genes, but not of the APC gene, in colon cancers with high-frequency microsatellite instability. J Exp Clin Cancer Res 2001; 20:553-9.

[15] Løvig T, Meling GI, Diep CB, Thorstensen L, Norheim Andersen S, Lothe RA, et al $A P C$ and $C T N N B 1$ mutations in a large series of sporadic colorectal carcinomas stratified by the microsatellite instability status. Scand J Gastroenterol 2002; 37:1184-93

[16] Luchtenborg M, Weijenberg MP, Wark PA, Saritas AM, Roemen GM, van Muijen GN, et al. Mutations in APC, CTNNB1 and K-ras genes and expression of hMLH1 in sporadic colorectal carcinomas from the Netherlands Cohort Study. BMC Cancer 2005; 5:160-70.

[17] Johnson V, Volikos E, Halford SE, Eftekhar Sadat ET, Popat S, Talbot I, et al. Exon 3 beta-catenin mutations are specifically associated with colorectal carcinomas in hereditary non-polyposis colorectal cancer syndrome. Gut 2005 54:264-7.

[18] Longacre TA, Fenoglio-Preiser CM. Mixed hyperplastic adenomatous polyps/ serrated adenomas. A distinct form of colorectal neoplasia. Am J Surg Pathol 1990; 14:524-37.

[19] Kambara T, Simms LA, Whitehall VLJ, Spring KJ, Wynter CV, Walsh MD, et al. $B R A F$ mutation is associated with DNA methylation in serrated polyps and cancers of the colorectum. Gut 2004; 53:1137-44.

[20] Jass JR. Classification of colorectal cancer based on correlation of clinical, morphological and molecular features. Histopathology 2007; 50:113-30.

[21] Chan TL, Zhao W, Leung SY, Yuen ST. BRAF and KRAS mutations in colorectal hyperplastic polyps and serrated adenomas. Cancer Res 2003; 63:4878-81.

[22] Yang S, Farraye FA, Mack C, Posnik O, O'Brien MJ. BRAF and KRAS mutations in hyperplastic polyps and serrated adenomas of the colorectum: relationship to 
histology and CpG island methylation status. Am J Surg Pathol 2004; 28 : 1452-9.

[23] Jass JR, Baker K, Zlobec I, Higuchi T, Barker M, Buchanan D, et al. Advanced colorectal polyps with the molecular and morphological features of serrated polyps and adenomas: concept of a 'fusion' pathway to colorectal cancer. Histopathology 2006; 49:121-31.

[24] Steinberg P, Scholtka B. Method for conducting non-invasive early detection of colon cancer and/or of colon cancer precursor. United States Patent and Trademark Office Application No. 10/573, 134; 2006.

[25] Schimanski CC, Linnemann U, Berger MR. Sensitive detection of K-ras mutations augments diagnosis of colorectal cancer metastases in the liver. Cancer Res 1999; 59:5169-75.

[26] Boland CR, Thibodeau SN, Hamilton SR, Sidransky D, Eshleman JR, Burt RW, et al. A National Cancer Institute Workshop on Microsatellite Instability for cancer detection and familial predisposition: development of international criteria for the determination of microsatellite instability in colorectal cancer. Cancer Res 1998; 58:5248-57.

[27] Davies H, Bignell GR, Cox C, Stephens P, Edkins S, Clegg S, et al. Mutations of the $B R A F$ gene in human cancer. Nature 2002; 417:949-54.

[28] Diergaarde B, van Geloof WL, van Muijen GN, Kok FJ, Kampman E. Dietary factors and the occurrence of truncating APC mutations in sporadic colon carcinomas: a Dutch population-based study. Carcinogenesis 2003; 24:283-90.

[29] Conlin A, Smith G, Carey FA, Wolf CR, Steele RJ. The prognostic significance of K-ras, p53, and APC mutations in colorectal carcinoma. Gut 2005; 54:1283-6.

[30] Deuter R, Müller O. Detection of APC mutations in stool DNA of patients with colorectal cancer by HD-PCR. Hum Mutat 1998; 11:84-9.

[31] Zhang B, Ougolkov A, Yamashita K, Takahashi Y, Mai M, Minamoto T. $\beta$-Catenin and ras oncogenes detect mos human colorectal cancer. Clin Cancer Res 2003; 9:3073-9.
[32] Domingo E, Espín E, Armengol M, Oliveira C, Pinto M, Duval A, et al. Activated $B R A F$ targets proximal colon tumors with mismatch repair deficiency and MLH1 inactivation. Genes Chromosomes Cancer 2004; 39:138-42.

[33] Fransén K, Klintenäs M, Osterström A, Dimberg J, Monstein HJ, Söderkvist P. Mutation analysis of the BRAF, ARAF and RAF-1 genes in human colorectal adenocarcinomas. Carcinogenesis 2004; 25:527-33.

[34] Sweeney C, Boucher KM, Samowitz WS, Wolff RK, Albertsen H, Curtin K, et al. Oncogenetic tree model of somatic mutations and DNA methylation in colon tumors. Genes Chromosomes Cancer 2009; 48:1-9.

[35] Thorstensen L, Lind GE, Løvig T, Diep CB, Meling GI, Rognum TO, et al. Genetic and epigenetic changes of components affecting the WNT pathway in colorectal carcinomas stratified by microsatellite instability. Neoplasia 2005; 7: 99-108.

[36] Konishi M, Kikuchi-Yanoshita R, Tanaka K, Muraoka M, Onda A, Okumura Y, et al. Molecular nature of colon tumors in hereditary nonpolyposis colon cancer, familial polyposis, and sporadic colon cancer. Gastroenterology 1996; 111:307-17.

[37] Jass JR, Biden KG, Cummings MC, Walsh M, Schoch E, Meltzer SJ, et al. Characterisation of a subtype of colorectal cancer combining features of the suppressor and mild mutator pathways. J Clin Pathol 1999; 52:455-60.

[38] Thibodeau SN, Bren G, Schaid D. Microsatellite instability in cancer of the proximal colon. Science 1993; 260:816-9.

[39] Kakiuchi H, Watanabe M, Ushijima T, Toyota M, Imai K, Weisburger JH, et al. Specific $5^{\prime}-G G G A-3^{\prime} \rightarrow 5^{\prime}-G G A-3^{\prime}$ mutation of the Apc gene in rat colon tumors induced by 2-amino-1-methyl-6-phenylimidazo[4,5-b]pyridine. Proc Natl Acad Sci USA 1995; 92:910-4.

[40] Burnouf DY, Miturski R, Nagao M, Nakagama H, Nothisen M, Wagner J, et al. Early detection of 2-amino-1-methyl-6-phenylimidazo(4,5-b)pyridine (PhIP)induced mutations within the Apc gene of rat colon. Carcinogenesis 2001; $22: 329-35$ 